\title{
Can We Progress from Solipsistic Science to Frugal Innovation?
}

\section{Citation}

Nocera, Daniel G. 2012. "Can We Progress from Solipsistic Science to Frugal Innovation?" Daedalus 141 (3): 45-52. https://doi.org/10.1162/daed_a_00160.

\section{Permanent link}

http://nrs.harvard.edu/urn-3:HUL.InstRepos:41461210

\section{Terms of Use}

This article was downloaded from Harvard University's DASH repository, and is made available under the terms and conditions applicable to Other Posted Material, as set forth at http:// nrs.harvard.edu/urn-3:HUL.InstRepos:dash.current.terms-of-use\#LAA

\section{Share Your Story}

The Harvard community has made this article openly available.

Please share how this access benefits you. Submit a story.

\section{Accessibility}




\title{
Can We Progress from Solipsistic Science to Frugal Innovation?
}

\author{
Daniel G. Nocera
}

Abstract: Energy demand in the twenty-first century will be driven by the needs of three billion people in the emerging world and three billion new inhabitants to our planet. To provide them with a renewable and sustainable energy supply is perhaps the greatest challenge for science in the twenty-first century. The science practiced to meet the energy needs of the twentieth century responded to a society of wealth, and energy systems were designed to be large and centralized. However, the inability of the emerging world to incur large capital costs suggests that a new science must be undertaken, one that does not rely on economy of scale but rather sets as its target highly manufacturable and distributed energy systems that are affordable to the poor. Only in this way can science provide global society with its most direct solution for a sustainable and carbon-neutral energy future.

DANIEL G. NOCERA, a Fellow of the American Academy since 2005, is the Henry Dreyfus Professor of Energy and Professor of Chemistry at the Massachusetts Institute of Technology, where he is also the Director of the Solar Revolutions Project and Director of the Eni Solar Frontiers Center. In Fall 2012, he moves to Harvard University and becomes the Patterson Rockwood Professor of Energy in the Department of Chemistry and Chemical Biology. He has conducted pioneering studies of the basic mechanisms of energy conversion in biology and chemistry, with a recent focus on the generation of solar fuels. He has published more than 325 articles and presented more than 650 invited lectures on topics relating to renewable energy.
Solipsism is "the view or theory that self is the only object of real knowledge or the only thing really existent." ${ }^{1}$ Deriving from the Latin sō-lus ("alone") and ipse ("self"), solipsism - in its most extreme form - drives one to question whether an external world exists outside the mind. In many ways, the twentieth century was the century of solipsistic science. Science was practiced for the part of society that the scientist lived in and could observe. Because typical science is an expensive endeavor, that society was in large part one of affluence. Indeed, the knowledge and technology generated from the science of the twentieth century has served the developed world well. Any scientific or technological advance that immediately comes to mind inevitably originates from a handful of territories (for example, North America, Europe, Russia, Japan) with relatively high GDPs. But the benefits of this work have had little crossover to the poorer parts of the less-developed world.

Arguably, the inability of twentieth-century science to penetrate the underdeveloped world is rooted in cost. Research has been preoccupied with

(C) 2012 by the American Academy of Arts \& Sciences 
Can We invariably expensive targets: the "best"

Progress or the "most efficient" for the materials from scientist, the "fastest" for the enzymoloScience to gist, the "biggest" for the high energy Frugal physicist, or the "smallest" for the Innovation? nanoscientist, to name a few. For this reason, science and technology in the last century served the needs defined by the voice of affluence. But a new voice is audible in the twenty-first century. It is a whisper now but soon will be a cacophony of overwhelming numbers. Will science respond to the needs of the underdeveloped and emerging world in the coming century, and will it do so with sufficient alacrity to address the most urgent issues affecting global society?

$\mathrm{N}$ owhere has science wandered further from the world it needs to serve than in the field of energy. Today you hear about the smart grid (at least we now admit to having lived with a dumb energy system during the twentieth century); energy efficiency through materials design; engineering technologies to deliver natural gas; and grid storage. All are important science and technology targets for those with access to energy. But they have little to do with the energy needs of our future global society.

Consider the following energy equation $^{2}$ :

$$
\dot{\mathrm{E}}=\mathrm{N} \times(\mathrm{GDP} / \mathrm{N}) \times(\dot{\mathrm{E}} / \mathrm{GDP})
$$

Here, $\dot{E}$ is energy consumption, $N$ is the global population, $G D P / N$ is the globally averaged GDP per capita, and $\dot{E} / G D P$ is the globally averaged energy intensity (that is, the energy consumed per unit of GDP). Carrying the numbers through the equation shows that our future global society will have an enormous appetite for energy. The rate of worldwide primary energy consumption will increase from 16.2 terawatts (TW; one TW equals one trillion watts, $1 \times 10^{12}$ watts, or $1 \times 10^{12}$ joules per second), as measured in 2007, to conservative estimates of $30 \mathrm{TW}$ by mid-century and $45 \mathrm{TW}$ by the end of the century. ${ }^{3}$ Most, if not all, of this demand is driven by the growing world population, which is projected to increase from 6.2 billion at the beginning of this century to approximately 9.4 billion by 2050.4 In addition to these three billion new inhabitants of the planet, three billion people in the emerging world will seek a rising standard of living. Because energy consumption scales directly with a country's GDP, energy use by developing nations will increase dramatically as they modernize. ${ }^{5}$ Geopolitical, environmental, and economic security will likely be realized only if science in the twenty-first century can meet the energy demands of these six billion additional energy users by supplying them with a sustainable and carbon-neutral energy source.

To do so requires a different mindset from the solipsistic science of the previous century. First, the energy challenge of the twenty-first century cannot be addressed from the myopic viewpoint of a researcher in the isolated laboratory environment. The energy equation must be treated holistically. To begin, we can recast the above equation in a less mathematical form:

$$
\begin{aligned}
& \dot{\mathrm{E}}=(\text { society/culture }) \times(\text { economics } / \text { policy }) \times \\
& (\text { science } / \text { innovation })
\end{aligned}
$$

Most energy research has emphasized the science/innovation part of this equation, with perhaps a modest nod by some in the direction of economics/policy; no approach has considered the first part of the equation. This fact is confounding, as the aspirations and needs of billions of people in emerging economies are what drive future global energy demand. If science is to have a timely and meaningful impact on society in this century, a number of questions must be considered, 
including how does science: affect population growth? empower and educate the poor, especially women? become adopted within different cultures? contribute to an integrative energy and technology policy? translate within the constraints imposed by international law? affect the balance of wealth? impact human health? These are a few of the broad contextual questions that will need to be addressed as part of the society/culture and economics/policy components of the energy equation.

Second, cost must be a driver for energy research in the twenty-first century. The development of inexpensive solar energy technologies, while beneficial to the legacy world, is at odds with the needs of the nonlegacy world. In legacy nations, energy systems of the past and present operate at large scale, are centralized, and distribute energy to the masses via an expensive and complex network. Such infrastructure is not viable in the near-term future of nonlegacy states, where it is cost prohibitive to build centralized energy and distribution systems. In 2007, the total value of generation, transmission, and distribution infrastructure for regulated electric utilities in the United States was $\$ 440$ billion; and capital expenditures exceeded $\$ 70$ billion. ${ }^{6}$ Reasonable recovery of capital expenditures requires designing energy systems that operate at large scale and high efficiency; consequently, energy systems of the legacy world come with significant balance-of-system (BOS) costs. Downscaling such technology for use in nonlegacy regions is not economically viable because the в OS costs do not scale commensurately. Thus, existing off-theshelf technologies will be difficult to adapt to low cost.

Rather, in order to be adaptable in the nonlegacy world, the disruptive energy technologies of the twenty-first century will necessarily be light and highly manufacturable as well as robust and low mainte- nance. Simply put, new research is needed Daniel G. to develop what I have called the "fast Nocera food" equivalent of energy systems 7 ; hence, the need for frugal innovation is at the fore. ${ }^{8}$ Science that targets frugal innovation provides a win-win situation for the legacy world as well. Established energy markets are slow to turn over because they require significant capital investment. Thus, the quickest path to market penetration in the legacy world is one of low cost. To meet the objectives of renewable, low-cost, and highly manufacturable energy systems, science in the twenty-first century will develop a practical and realistic energy infrastructure for both nonlegacy and legacy worlds.

Third, the shift to frugal innovation sets a different design target for the research scientist. The most impactful scientific discoveries in the twenty-first century will involve working backward from a technology target. To this end, the research scientist must consider systems engineering from the outset. Discovery must cast an eye toward implementation under simply engineered conditions so that BOS costs remain low. Yet this objective is largely absent from current scientific practice. Consider the materials science of photovoltaics, that is, the process of converting sunlight into electricity. How often does one hear that solar panels are expensive and that there is a need for science to create a cheaper photovoltaic material? But analysis of the numbers suggests a disconnect in the logic of this statement. The cost of generating photovoltaic electricity from known semiconducting materials is plummeting; moreover, the cost of the photovoltaic semiconductor is less than 10 percent that of the module (the solar panel), its installation, and its maintenance combined. 9

This does not mean that the search for new photovoltaic materials should cease. Indeed, it should continue, but not neces- 
Can We sarily with the target of a cheaper mate-

Progress
from

Science to the fabrication process of the photovolta-

Frugal ic module as we now know it - thus yielding much more significant cost reductions. This is a different imperative for the researcher who wishes to make an impact in photovoltaics, especially one who wishes to help the poor. If scientists in the twentieth century expressed a desire to "make a cheaper photovoltaic material for solar modules," then scientists in this century must instead strive to "make a photovoltaic material that allows solar modules to be made more cheaply." This is only one example of many that could be enumerated. Unfortunately, most researchers do not understand such distinctions and consider them to be nuance. But in the twenty-first century, scientists must consider the "systems engineering" aspect of the technologies that their discoveries will target.

\section{W} for energy science in the twenty-first century?

(1) Solar energy. Delivering an additional $16 \mathrm{TW}$ to our world by 2050 is not a simple task. As has now been documented extensively, most energy sources are insufficient to keep pace with the growing global appetite for energy. ${ }^{10}$ Conventional biomass is a limited energy source owing to the low energy efficiency of photosynthesis. ${ }^{11}$ Nuclear energy requires a large number of sites that will be difficult to build fast enough to keep up with energy demand. ${ }^{12}$ Moreover, a nuclearbased energy supply will require widespread public acceptance. ${ }^{13}$ Finally, tides, wind, and other natural forces have too low an energy density to satiate demand. ${ }^{14}$ These shortcomings, however, do not mean that continued research into such carbon-neutral energy supplies should be abandoned. If these resources are available, then they should be exploited. Indeed, they will be utilized by industry because the fundamental science for many of them has largely been developed.

But the fundamental research scientist should be at the frontier where industry is too nervous to venture. For this reason, and because of its enormous potential, solar energy will be the preeminent carbon-neutral energy source for research in the twenty-first century. Terrestrial solar insolation - that is, the solar radiation that reaches Earth's surface - exceeds the resource base of all other renewable energy sources combined. Additionally, it far exceeds what is necessary to support even the most technologically advanced society. The ability of solar radiation to meet future global energy demand is well documented. ${ }^{15}$ But it needs to be developed strategically, with an emphasis on the nonlegacy world. An especially attractive approach is the idea of personalized energy, which would replace the centralized energy system of the twentieth century in much the same way that personal computers replaced the mainframes of the 1970s. ${ }^{16}$

Because energy use scales with wealth, point-of-use solar energy will put individuals, in the smallest village in the nonlegacy world and in the largest city of the legacy world, on a more level playing field. Moreover, personalized energy is secure because it is highly distributed and gives individuals control over the energy they rely on. And personalized energy can reach the six billion new energy users of this century via high-throughput manufacturing of distributed energy systems. However, major challenges confront the deployment of personalized solar energy on a large and distributed scale. The imperative to science is to develop new materials, reactions, and processes that enable solar energy to be sufficiently inexpensive 
to penetrate global energy markets. Most, if not all, of these materials and processes entail a metallic or noncarbon-based main group element. Accordingly, the subject of inorganic chemistry will be especially germane to delivering personalized solar energy to our planet.

As discussed above, solar modules are indeed too expensive for the poor. New photovoltaic materials need to be developed that permit solar-to-current conversion with lower-cost modules, or with entirely new design approaches, such as nanoparticle-based systems, thus eliminating the BOs costs that plague current photovoltaic technology. Because society relies on a continuous energy supply and solar energy is diurnal as well as subject to intermittency arising from variable atmospheric conditions, an inexpensive storage mechanism is needed for solar energy to be a truly useful contributor to the primary energy supply. Unfortunately, most current methods of solar storage, including batteries, are characterized by energy densities that are too low for largescale solar storage. ${ }^{17}$ Conversely, the energy density of fuels is one hundred to one thousand times larger than that of any other storage method. Indeed, society has intuitively understood this disparity in energy density; all large-scale energy storage developed over the last century is in the form of fuels. But these fuels are carbon-based. The challenge for the discipline of chemistry (via new catalysis), and for science more generally, is to develop solar-to-fuels storage processes, such as creation of the artificial leaf, ${ }^{18}$ that are low cost and adaptable to a distributed energy infrastructure.

Finally, although biomass is certainly a distributed solar-to-fuels energy source, any natural photosynthetic process is plagued by low efficiency (a theoretical maximal thermodynamic power conversion efficiency of roughly 10 percent, with the best-growing plants never exceeding Daniel G. 1 to 3 percent and algae at about 5 per- Nocera cent). ${ }^{19}$ As is true of most living organisms, the plant or alga needs to use its stored energy for its cellular growth and maintenance. Synthetic biology provides exciting opportunities to radically redesign the photosynthetic apparatus to substantially improve the efficiency of natural photosynthesis.

(2) Energy efficiency. When industrialized society developed in the twentieth century, energy was not at a premium. Yet a tidal shift in energy costs is already apparent at the beginning of the twentyfirst century. Industrial titans have challenged their employees to maintain production with 30,50 , and even 60 percent reductions in energy use in the coming decade. This challenge will require more energy-efficient materials and processes. Some avenues for research are obvious: for instance, the creation of better thermoelectric materials, which are able to convert temperature differences to electricity and vice versa. ${ }^{20}$ But there are grander issues to tackle with regard to energy efficiency, and these will require a more profound change in the way we approach our professions.

Nowhere is this need for change better exemplified than in the petrochemical industry. Many of the products we use in modern society are derived from petroleum feedstocks. Plastics are exemplars. Very long chain hydrocarbons present in petroleum are broken down or "cracked" into $\mathrm{C}_{2}$ and $\mathrm{C}_{3}$ subunits (ethylene and propylene). An exquisite science in the twentieth century was developed to stitch the $C_{2}$ and $C_{3}$ subunits back together to furnish a variety of polymers with a desired property. Industry could pursue this approach because energy and petrochemicals were cheap. Nevertheless, the process is the model of inefficiency: a significant amount of energy is needed to 
Can We break the carbon-carbon bond, and still

Progress more energy is needed to put the carbon Solipsistic atoms back together into the long chains Science to that compose the plastic. As energy and Frugal Innovation petrochemicals become more expensive, the cost of creating materials derived from them will rise. Thus, a new organic chemistry must develop around different feedstocks. This will require the creation of an enormous amount of fundamental new science.

As a case in point, despite amazing advances in synthetic methodologies that led to the birth of the pharmaceutical industry in the twentieth century, the organic chemist of today is hard-pressed to take the simplest of hydrocarbons (for example, hexane), activate their $\mathrm{CH}$ bonds, and join them with a defined connectivity. This is only one example of manufacturing inefficiency, which is the rule rather than the exception. Why are such inefficient practices so common? The answer is that energy in the twentieth century was simply too cheap. The twenty-first century will require a seismic shift in the way organic chemistry is executed. Thus, entire industries will have to rely on basic science in order to reinvent themselves in an energy-deprived world.

(3) Materials sustainability. Energy is the first resource to leak through the cracks in the dam of sustainability. The energy challenge of the twenty-first century is in large part due to overpopulation of our planet. And with population growth on the rise, many more cracks will appear in the sustainability dam - and a host of new challenges will soon follow. The criticality of water resources is coming into focus, ${ }^{21}$ with food not far behind. ${ }^{22}$ Yet there are more subtle materials sustainability challenges, too. How many realize that the availability of elements such as phosphorus will be a major problem in the twenty-first century? This biocritical element is in short supply because of geo- logical and terrestrial variations in the phosphorus cycle, such as changes caused by the erosion that results from agriculture and human activity. ${ }^{23}$ The net transfer of dissolved phosphorus from land to the oceans is 4 to 6 teragrams per year, which represents a doubling of prehuman input fluxes. Considering the importance of phosphorus in life cycles and fertilization, new chemistries must be developed for phosphorus recovery. In short, changes in Earth systems will drive a need for new basic science focused on element and materials recovery.

Some think that supplying energy to the poor will only exacerbate the sustainability problem. With more energy will come more demand. But we need to return to the energy equation. When people have access to energy, they are able to increase wealth. Study after study has shown that when people are empowered, they seek access to education. And education leads to declining birth rates. So by undertaking a science to provide energy to the poor, we establish a positive feedback loop that most directly addresses the sustainability issue.

In doing so, we avoid the possible future Kurt Vonnegut depicted shortly before his death. In words both chilling and consoling, Vonnegut described the planet as a living organism. ${ }^{24} \mathrm{He}$ reminded us that when an organism is sufficiently compromised, its immune system responds by eliminating irksome intruders. Viewing humans as the irksome intruder on our planet-organism, Vonnegut assured us that we need not worry about the planet. When we become sufficiently intolerable, the planet's immune system will respond, eliminating humans by not sustaining us in the dramatically altered environment that we have created.

Earth will continue to exist and flourish at high carbon dioxide levels and with a radically different environment, though 
not as we know it. It is the human species, on the other hand, that is in a precarious state. When confronted about a solution, Vonnegut responded that the concerned among us should "get a gang" and do something about it. The "gang" of scientists who take up Vonnegut's call to arms must free themselves from the bonds of solipsism. They must consider all components of the energy equation in practicing their craft, leaving behind a with- ered brand of twentieth-century practice Daniel G. - solipsistic science - and embrace a new Nocera brand of science for the twenty-first century: frugal innovation. In this way, they will provide the technology needed to answer the greatest challenges confronting humanity in the twenty-first century, not the least of which will be to secure a renewable and sustainable energy supply for the nonlegacy world.

\section{ENDNOTES}

1 "Solipsism," in The Oxford English Dictionary, 2nd ed. (Oxford: Clarendon Press, 1989); online version updated March 2012, http://www.oed.com/view/Entry/184295.

${ }^{2}$ Martin I. Hoffert, Ken Caldeira, Atul K. Jain, Erik F. Haites, L.D. Danny Harvey, Seth D. Potter, Michael E. Schlesinger, Stephen H. Schneider, Robert G. Watts, Tom M.L. Wigley, and Donald J. Wuebbles, "Energy Implications of Future Stabilization of Atmospheric $\mathrm{CO}_{2}$ Content,” Nature 395 (6705) (October 29, 1998): 881-884.

3 Nathan S. Lewis and Daniel G. Nocera, "Powering the Planet: Chemical Challenges in Solar Energy Utilization," Proceedings of the National Academy of Sciences 103 (43) (October 24, 2006): 15729-15735.

42009 World Population Data Sheet (Washington, D.C.: Population Reference Bureau, 2009), http://www.prb.org.

5 Daniel G. Nocera, “On the Future of Global Energy,” Daedalus 135 (4) (Fall 2006): 112 - 115.

6 Marc Chupka and Gregory Basheda, "Rising Utility Construction Costs : Sources and Impacts," The Brattle Group (Washington, D.C.: The Edison Foundation, September 2007).

7 Daniel G. Nocera, “Fast Food Energy,” Energy \& Environmental Science 3 (8) (September 2010): 993-995.

8 Ratan Tata, "Out of India," The Economist, March 3, 2011.

9 Doug M. Powell, Mark T. Winkler, Hyunjoo Choi, Christie B. Simmons, David Berney Needleman, and Tonio Buonassisi, "Crystalline Silicon Photovoltaics : A Cost Analysis Framework for Determining Technology Pathways to Reach Baseload Electricity Costs,” Energy \& Environmental Science 5 (3) (March 2012):5874-5883.

10 Lewis and Nocera, "Powering the Planet"; Derek Abbott, "Keeping the Energy Debate Clean: How Do We Supply the World's Energy Needs?" Proceedings of the IEEE 98 (1) (January 2010): 42-66 ; Richard E. Smalley, "Future Global Energy Prosperity: The Terawatt Challenge," Materials Research Society Bulletin 30 (6) (June 2005): 412 - 417.

11 Robert E. Blankenship, David M. Tiede, James Barber, Gary W. Brudvig, Graham Fleming, Maria Ghirardi, M. R. Gunner, Wolfgang Junge, David M. Kramer, Anastasios Melis, Thomas A. Moore, Christopher C. Moser, Daniel G. Nocera, Arthur J. Nozik, Donald R. Ort, William W. Parson, Roger C. Prince, and Richard T. Sayre, "Comparing Photosynthetic and Photovoltaic Efficiencies and Recognizing the Potential for Improvement," Science 332 (6031) (May 13, 2011): $805-809$.

12 Derek Abbott, "Is Nuclear Power Globally Scalable?” Proceedings of the IEEE 99 (10) (October 2010): $1611-1617$. 
Can We 13 Stephen Ansolabehere, John Deutch, Michael Driscoll, Paul E. Gray, John P. Holdren, Paul L. Progress Joskow, Richard K. Lester, Ernest J. Moniz, and Neil E. Todreas, The Future of Nuclear Power: from An Interdisciplinary MIT Study (Cambridge, Mass. : MIT Press, 2003).

Science to 14 Abbott, "Keeping the Energy Debate Clean”; Abbott, "Is Nuclear Power Globally Scalable?" Natural and Artificial,” Chemical Society Reviews 38 (1) (January 2009): 185-196.

16 Daniel G. Nocera, "Personalized Energy: The Home as a Solar Power Station and Solar Gas Station," ChemSusChem 2 (5) (May 25, 2009): 387-390; Daniel G. Nocera, "Chemistry of Personalized Solar Energy," Inorganic Chemistry 48 (21) (November 2, 2009): 10001 - 10017.

17 Timothy R. Cook, Dilek K. Dogutan, Steven Y. Reece, Yogesh Surendranath, Thomas S. Teets, and Daniel G. Nocera, "Solar Energy Supply and Storage for the Legacy and Nonlegacy World," Chemical Reviews 110 (11) (November 2010): 6474-6502.

18 Steven Y. Reece, Jonathan A. Hamel, Kimberly Sung, Thomas D. Jarvi, Arthur J. Esswein, Joep J.H. Pijpers, and Daniel G. Nocera, "Wireless Solar Water Splitting Using Silicon-Based Semiconductors and Earth Abundant Catalysts," Science 334 (6056) (November 4, 2011): 645 648; Daniel G. Nocera, “The Artificial Leaf," Accounts of Chemical Research 45 (April 4, 2012): $767-776$.

19 Blankenship et al., "Comparing Photosynthetic and Photovoltaic Efficiencies and Recognizing the Potential for Improvement."

20 Jeffrey G. Snyder and Eric S. Toberer, “Complex Thermoelectric Materials,” Nature Materials 7 (2) (February 2008): $105-114$.

21 Charles J. Vörösmarty, Pamela Green, Joseph Salisbury, and Richard B. Lammers, "Global Water Resources: Vulnerability from Climate Change and Population Growth," Science 289 (5477) (July 14, 2000): 284-288.

${ }^{22}$ H. Charles J. Godfray, John R. Beddington, Ian R. Crute, Lawrence Haddad, David Lawrence, James F. Muir, Jules Pretty, Sherman Robinson, Sandy M. Thomas, and Camilla Toulmin, "Food Security: The Challenge of Feeding 9 Billion People," Science 327 (5967) (February 12, 2010): $812-818$.

23 Gabriel M. Filippelli, “The Global Phosphorus Cycle: Past, Present, and Future,” Elements 4 (2) (April 2008): 89-95.

24 An interview with Kurt Vonnegut, by David Brancaccio, PBS NOW, October 7, 2005. 